\title{
Patrimonio urbano: la ciudad sostenida en tiempos de lo sostenible
}

Blanca del Espino Hidalgo | Dpto. Urbanística y Ordenación del Territorio, Universidad de Sevilla

URL de la contribución <www.iaph.es/revistaph/index.php/revistaph/article/view/3599>

En tiempos en que la escasez de medios -económicos, sociales, ambientales- ocupa el centro del debate político y ciudadano, cabe cuestionarnos una vez más cuál es el sentido de la conservación del patrimonio en contextos urbanos en los que la propia revelación de un nuevo elemento -ya sea por definirse en él valores patrimoniales emergentes, ya porque el hallazgo de un yacimiento arqueológico entre el conflicto con una necesidad, a priori, imperiosa- supone, para el común de la opinión pública y para un buen número de profesionales, la generación de un problema ante la gestión, tutela, conservación, documentación o viabilidad de lo que, después de siglos de defensa y en tiempos de bonanza, había llegado a ser reconocido como un recurso.

La propia divulgación de este concepto -el del patrimonio entendido como recurso- constituye, aún hoy, una poderosa arma de doble filo: si bien el entendimiento de herencias comunes e identidades compartidas ha dado pie a un sinfín de nuevas iniciativas sociales y culturales y, en abundantes ocasiones, ha permitido la regeneración socioeconómica de tejidos urbanos degradados con excelentes resultados -haciendo uso de las nuevas dinámicas culturales y del relativamente reciente fenómeno del turismo patrimonial-, la consideración del patrimonio como objeto de mercado ha supuesto, en muchos casos, la pérdida de valores de autenticidad y de su función social, cuando no la aparición de procesos de sobra conocidos como sería la gentrificación de los centros históricos urbanos, convertidos en adalides de una nueva modernidad en la que lo vintage sustituye a lo futurista y lo patrimonial queda relegado a una mera condición decorativa o pictórica en la que poco importan el valor de uso o su perduración en el tiempo, en el que habitar un fragmento de ciudad patrimonial se convierte en la nueva insignia de una contemporaneidad que se ha aburrido de los ensanches, la vida rural y el extrarradio.
Atendamos, en primer lugar, a la génesis del concepto de patrimonio, enunciado por primera vez en el derecho romano de la República, referido a la propiedad de los patricios (de pater, padre), que se transmitía de generación en generación a todos los miembros de una familia (ENGELS, 2008). Posteriormente se ha generalizado el uso del término, siendo dos de sus acepciones más comunes la del conjunto de bienes de carácter cultural de una comunidad, así como la propiedad de un individuo. Es, posiblemente, esta segunda consideración -entender que, como herencia que se transmite del padre al hijo, corresponde al segundo su tutela y valoración o, en cambio, su permuta por otros bienes materiales cualesquiera- la que engendre un mayor riesgo para el mismo en la actualidad. Pero en la definición primigenia ya aparecen las dos características principales del patrimonio histórico tal y como lo conocemos hoy: de un lado el aprecio de los bienes y, de otro, su vocación trascendental, algo que recibimos de nuestros padres y que transmitiremos a nuestros hijos.

Sirvan como ilustración de esto último las conocidas palabras con las que el romano Belisario se dirige al godo Totila ante la inminente invasión de su ciudad y el peligro de desaparición de su legado: "[...] quien arruinase tantas grandezas, sería reo de un grave delito contra todos los hombres del futuro, pues privaría de su valor a los abuelos e impediría a los nietos disfrutar de la vista de las excelsas obras de sus antecesores [...] Destruyendo Roma no pierdes una ciudad de otros, pierdes tu propia ciudad... Conservándola te enriqueces fácilmente con la posesión más espléndida del mundo [...]" (PROCOPIUS, 2000).

Llama la atención, por otra parte, el perfecto paralelismo entre la consideración de lo patrimonial y la definición que desde organismos oficiales se da para uno de los grandes conceptos que estructuran, a día de hoy, los 
a debate Preexistencias en la ciudad histórica contemporánea: viabilidad y convivencia

| coordinan Plácido González Martínez, Miguel Ángel Tabales Rodríguez

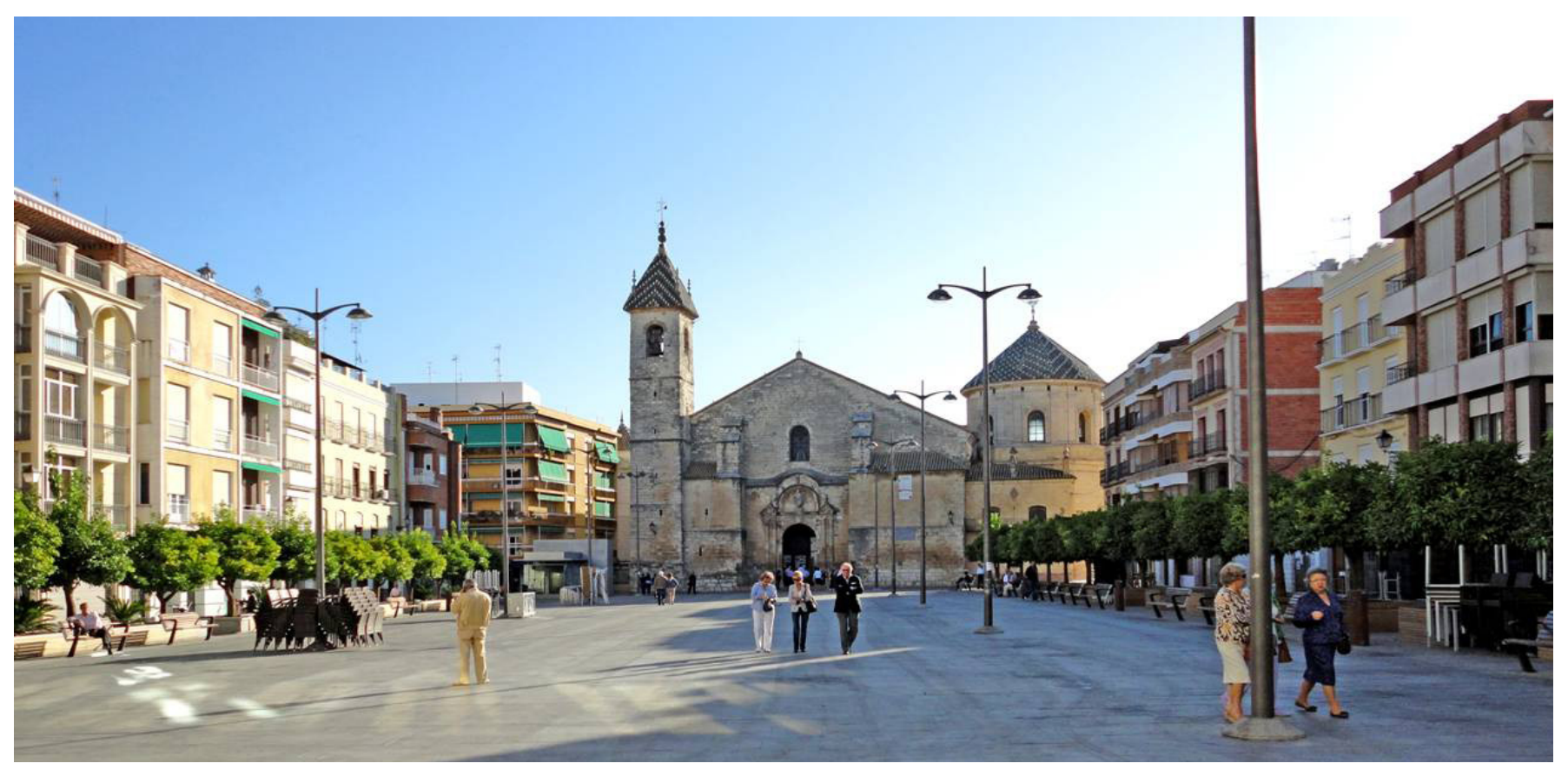

Templo parroquial de San Mateo (Lucena, Córdoba) como telón de fondo de la destrucción y sustitución del patrimonio residencial de la Plaza Nueva | foto Blanca del Espino Hidalgo

discursos que defienden a la eficiencia por encima de cualquier otra consideración para conseguir un equilibrio en las formas de vida actuales: la sostenibilidad. Así, la expresión "desarrollo sostenible" se aplica generalmente a los ámbitos ambiental y económico y fue acuñada por primera vez en el Informe titulado Nuestro futuro común, como "la satisfacción de las necesidades de las generaciones presentes sin comprometer las posibilidades de las del futuro para atender sus propias necesidades" (COMMON FUTURE, 1987).

Así pues, incluso desde sus definiciones oficiales $u$ oficiosas, ambos conceptos se refieren a algo que recibimos, que mantenemos y cuidamos, y que daremos a manos posteriores. Una suerte de herencia, de sentido de la continuidad, de conciencia de responsabilidad en la tutela, que resulta idéntico en ambos casos y que lleva a la idea de que, prácticamente, el patrimonio contiene de forma inherente las raíces de la sostenibilidad o, lo que es igual, lo patrimonial es, por sí mismo, sostenible. Esto nos llevaría a un cambio de paradigma en el que la idea de que la conservación de la ciudad patrimonial es poco eficiente -o insostenible- queda superada por la consideración de que la que hemos heredado es, en sí misma, la ciudad sostenida; es decir, aquello que ha permanecido entre nosotros de generación en generación y que, como Totila, desaprovecharíamos de no legar al futuro. La conservación del patrimonio no es un hecho forzado sino, al contrario, un proceso natural en el que llega hasta nosotros aquello que, por las razones que sean, ha merecido su permanencia o ha conseguido, en una suerte de selección natural de lo construido, llegar a este momento en el que los mecanismos de destrucción y sustitución resultan enormemente veloces.

Tratar los encuentros entre la ciudad histórica y la contemporánea no como un obstáculo, sino como un hecho natural pasa, también, por el entendimiento de la cultura como "el modo en que el hombre se ha adaptado al medio, es decir, su forma particular de adaptación al mismo y su medio de subsistencia en términos ambientales, económicos y sociales" (BOKOVA, 2013), aque- 


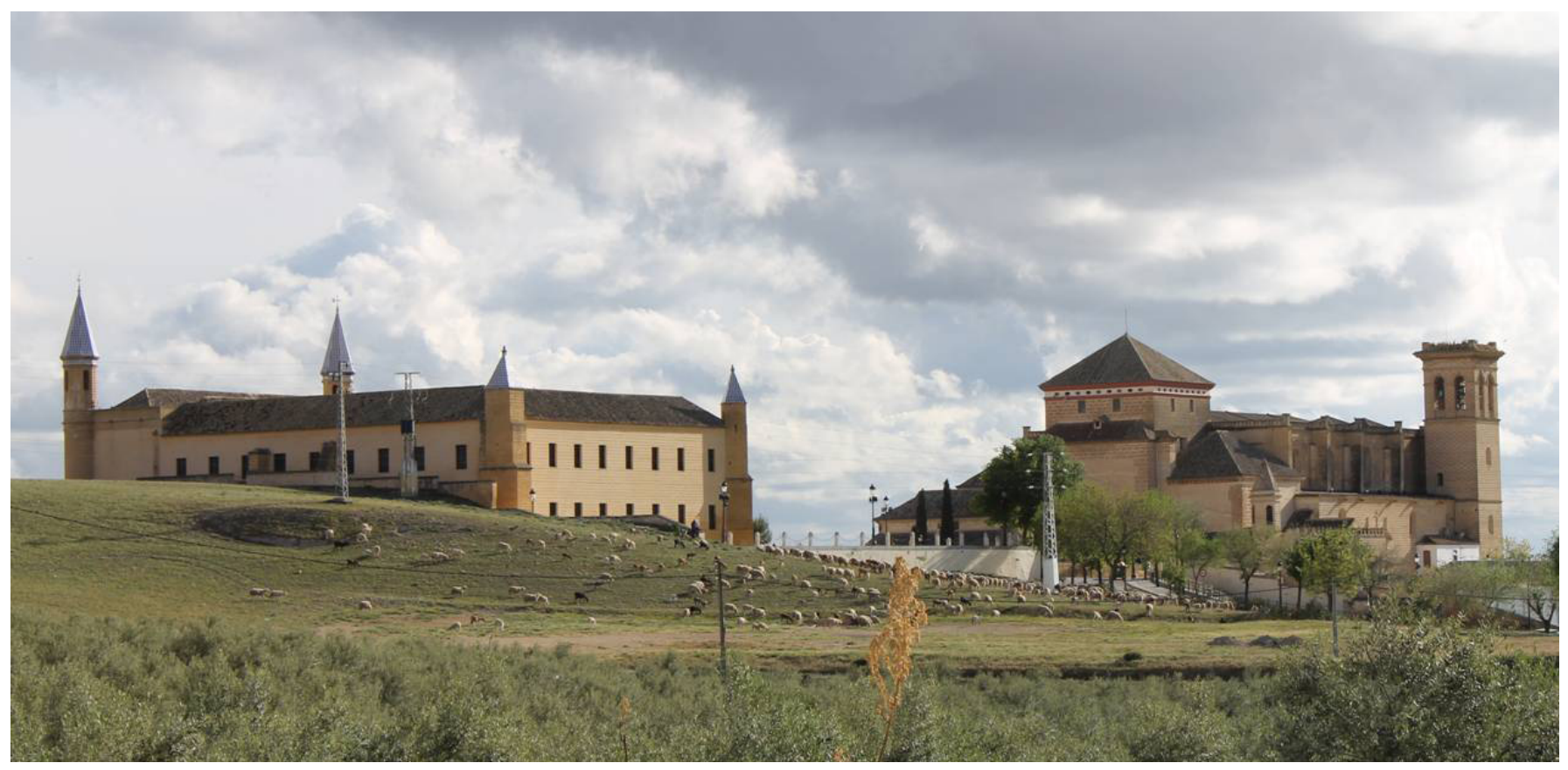

Vista norte del conjunto patrimonial de Osuna. Apropiación del entorno monumental por parte de las infraestructuras energéticas y la ganadería | foto Blanca del Espino Hidalgo

Ilo que nos revela la importancia de lo heredado y, en definitiva, del patrimonio, no sólo como reflejo de nuestro pasado sino, muy especialmente, como herramienta para nuestro futuro.

\section{BIBLIOGRAFÍA}

- BoKovA, I. (2013) Prólogo. En Textos fundamentales de la Convención de 2005 sobre la Protección y la Promoción de la Diversidad de las Expresiones Culturales. París: UNESCO, 2013 <http://unesdoc.unesco.org/images/0022/002253/22538 3S.pdf> [Consulta: 16/02/2015]

- Our COMMON FUTURE (1987) Oxford: Oxford University Press, 1987. Disponible también en <http://www.un-documents. net/our-common-future.pdf> [Consulta: 16/02/2015]

- ENGELS, F. (2008) La Gens y el Estado en Roma. En El origen de la familia, la propiedad privada y el estado. Madrid: Alianza Editorial, 2008, capítulo VI (El libro de bolsillo. Antropología; 3021)

- PROCOPIUS (2000) Guerra Gótica. En Historia de las guerras. Circa 546 d. de C. Madrid: Gredos, 2000-2007, t. 3. Libros V-VI, guerra gótica (390р.) (Biblioteca clásica Gredos; $280,282,355,358$ ) 